\title{
China and Japan
}

T The first missionary in China, near the end of the Ming dynasty, was the Italian Jesuit Matteo Ricci (1552-1610), who disseminated knowledge of western science - especially in mathematics, astronomy, and geography. His most important contribution was an oral Chinese translation of the first six books of Euclid's Elements, which was recorded by Xu Guangqi (1562-1633), scholar and scientist and Grand Secretary of the Wen Yuan Institute, and the 'first man in China after the monarch himself'. By the

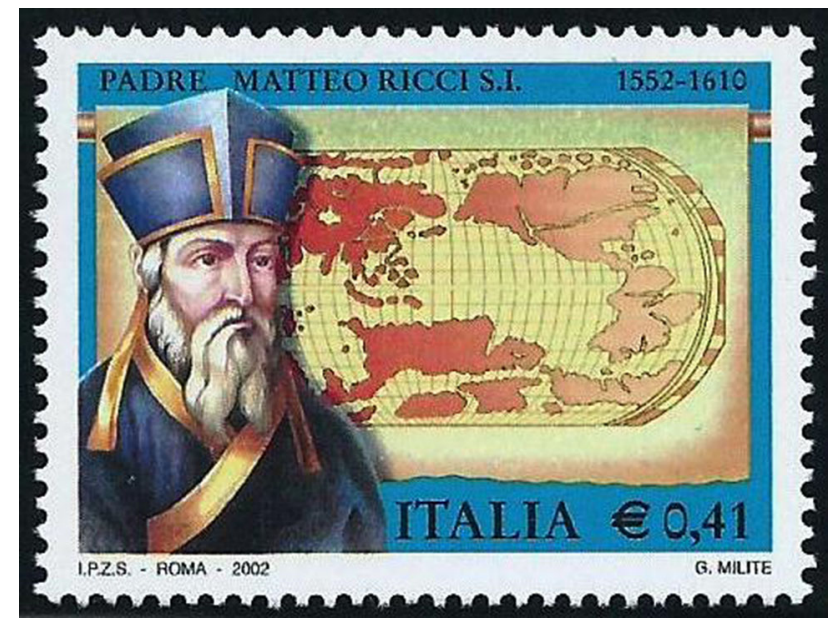

Ricci and world map

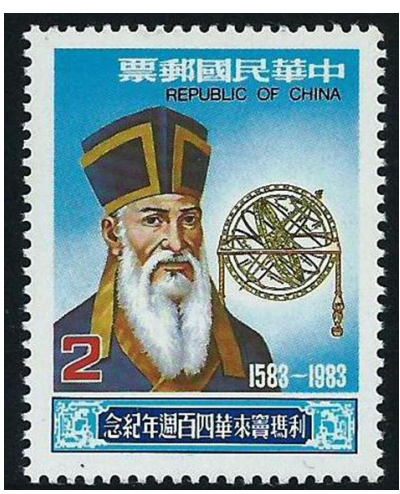

Ricci and astrolabe

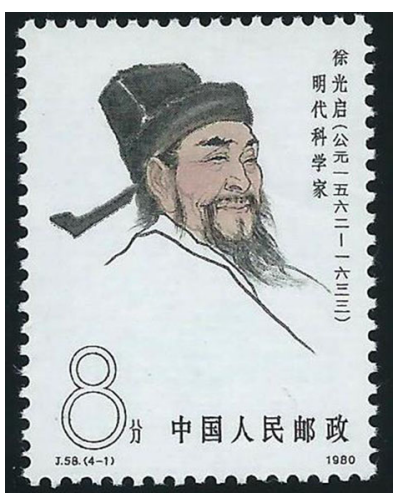

Xu Guangqi

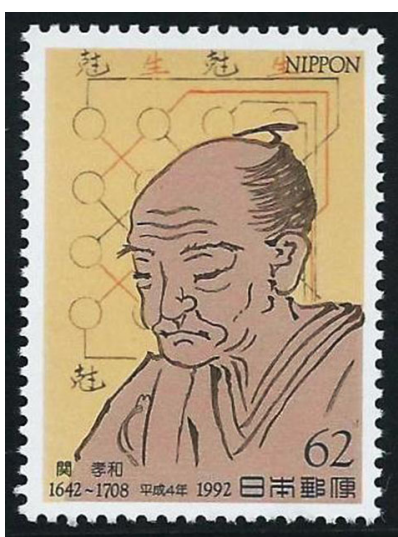

Takakazu Seki

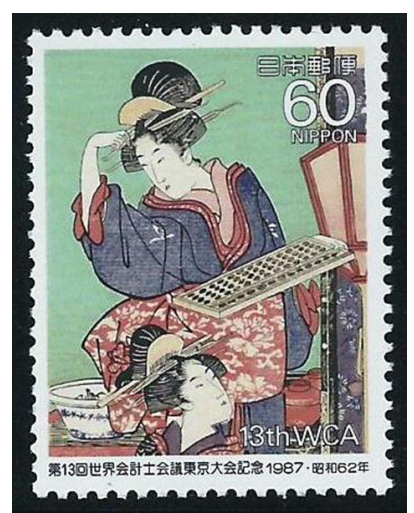

Japanese abacus

> Column editor's address: Robin Wilson, Mathematical Institute,

Andrew Wiles Building, University of Oxford, UK

e-mail: r.j.wilson@open.ac.uk

time of Ricci's arrival in China, the Chinese calendar had become very inaccurate, and Xu Guangqi was appointed to direct its reform.

Determinants are algebraic expressions that arise in the solution of systems of simultaneous linear equations. The Japanese mathematician Takakazu Seki (1642-1708), or Seki Kowa, seems to have been the first mathematician to investigate them, a few years before Leibniz (who is sometimes given priority) contributed to the subject. In 1683 Seki explained how to calculate determinants of up to size $5 \times 5$. The Japanese stamp includes his diagram for calculating the products that arise in the evaluation of $4 \times 4$ determinants.

The Japanese abacus, or soroban, appears here in a detail from the Three Beauties by Toyokuni Utagawa, from around 1800 .

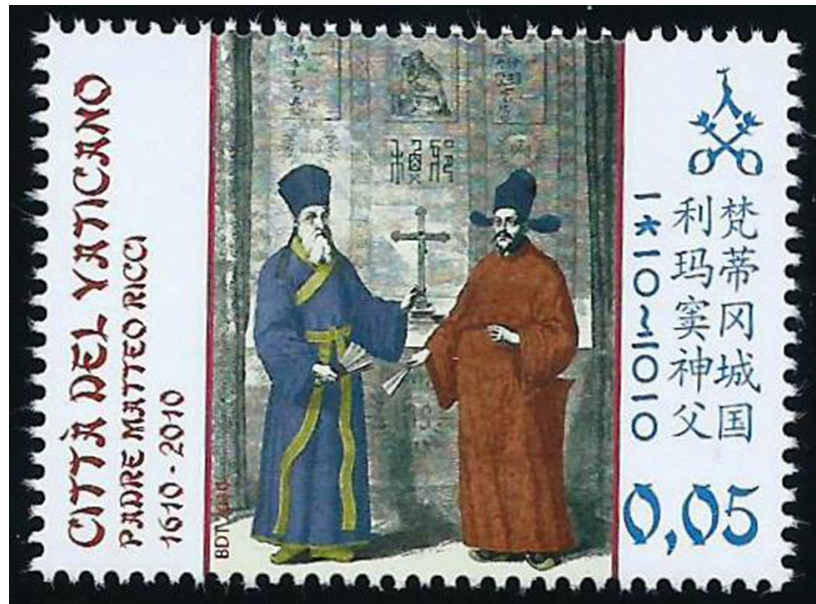

Ricci and Xu Guangqi 